\title{
"Com Cristo estou crucificado" (GI 2,19b) Novidade semântica e hermenêutica de um lexema e consciência mística do apóstolo Paulo
}

\author{
"With Christ I am crucified" (GI 2,19b) \\ Semantic and hermeneutic novelty of a lexeme \\ and mystical consciousness of the apostle Paul
}

Luís Henrique Eloy e Silva

\section{Resumo}

A discussão sobre a mística do apóstolo Paulo não passa pela compreensão das religiões mistéricas helenistas nem simplesmente pela compreensão religiosa do judaísmo, mas por sua experiência de Cristo, o Senhor crucificadoressuscitado, que transformou sua vida. O ponto de partida de tal compreensão é a cruz, que para o apóstolo não é a cruz do discípulo, mas é a cruz de Cristo com o qual Paulo está crucificado. No estar crucificado, o apóstolo encontra sua identidade e o sentido de sua vida. Da compreensão de tal realidade nasce o que chamamos de "consciência mística".

Palavras-chave: Exegese de Gl 2,19b-20. Consciência mística de Paulo. Espiritualidade Paulina.

\section{Abstract}

The discussion about the mystic of Paul, the apostle, does not go through the understanding of the Hellenistic mystery religions nor just through religious understanding of Judaism, but through his experience of Christ, the crucifiedrisen Lord, who changed his life. The starting point of such a comprehension 
is the cross, which for the apostle is not the cross of the disciple, but the cross of Christ, with whom Paul has been crucified. In being crucified, the apostle finds his identity and the meaning of his life. From the understanding of this reality arises what we call "mystical consciousness".

Keywords: Exegesis of Gal 2,19b-20. Paul's Mystical Consciousness. Pauline Spirituality.

\section{Introdução}

Embora Paulo não se tenha tornado mártir pela cruz, pois não morreu crucificado, o tema do estar crucificado com Cristo é um dos elementos mais instigadores de sua autocompreensão e consciência apostólica e toca intimamente seu caminho de crescente união com Cristo. Particularmente em Gl 2,19b-20, deparamo-nos com os temas do morrer e viver em Cristo, vinculados ao campo semântico da cruz e da ressurreição, temas esses inerentes, entre outras coisas, à discussão do misticismo paulino. ${ }^{1}$

Quando nos referimos ao termo mística neste artigo, partimos do pressuposto de que a compreensão da mística paulina não se deve basear na especulação de êxtases vivenciados ou não pelo apóstolo, nem tampouco na busca da linguagem mistérica presente em suas cartas. Muito pelo contrário, como já defendia Schweitzer, o ponto de partida da mística paulina deve fundamentar-se na compreensão que Paulo tem da condição daquele que crê, no hoje de sua existência; hoje que se localiza entre o ato da justificação e a esperança da libertação escatológica. ${ }^{2}$

O estudo da mística em Paulo teve seu referencial teórico inicial na obra de Adolf Deissman que se ocupou da fórmula paulina "em Cristo Jesus" no sentido de que o adjunto adverbial de lugar traria uma dimensão concomitantemente locativa do Cristo espiritual. ${ }^{3}$ Bem posteriormente, o tema foi retoma-

\footnotetext{
${ }^{1}$ Cf. O’BRIEN, P. T. “Misticismo”. In: HAWTHORNE, G. F.; MARTIN, R. P.; REID, D. G. (Orgs.). Dicionário de Paulo e suas Cartas. São Paulo: Paulus; Edições Vida Nova; Edições Loyola, 2008, p. 844.

${ }^{2}$ Cf. MARGUERAT, D. "La mystique de l'apôtre Paul”. In: SCHLOSSER, J. (Ed.). Paul de Tarse. Actes du XVIe Congrés de l'Association Catholique Française por l'Étude de la Bible. Paris: Les éditions du Cerf, 1996, p. 311.

${ }^{3}$ Cf. DEISSMANN, A. Die neutestamentliche Formel “in Christo Jesu”. Marburg: N. G. Elwert, 1892, p. 97.
} 
do por Richard Reitzenstein com a visão de que Paulo se enquadraria no misticismo helenístico oriental, particularmente no ambiente dos cultos mistéricos, e na gnose hermética expressa em Poimandres. ${ }^{4} \mathrm{~A}$ essas posições não faltaram reações contrárias, ${ }^{5}$ dentre as quais o estudo mais significativo é o de Albert Schweitzer em que ele não só reposiciona Paulo em um ambiente judaico mas relaciona-o com temas de fundo escatológico. ${ }^{6}$ Nesse sentido, a ressurreição é vista como a manifestação concreta da realidade escatológica na história e marca o início do mundo que há de vir. ${ }^{7}$ Por isso, mesmo na contingência da temporalidade, o cristão vive "em Cristo" a eternidade da atemporalidade que é "realidade realizada" por meio da união com Cristo e "realidade irrealizada" enquanto a parusia não chega. Em Cristo, o cristão faz a experiência de si mesmo como um novo ser. E, mesmo vivendo na temporalidade, pelo batismo passa a fazer parte do mistério da vida de Cristo, no qual, como filho de Deus, vive a esperança do que está preparado para os filhos na casa eterna do Pai. ${ }^{8}$

$\mathrm{Na}$ linha de Schweitzer, que se opôs à colocação da mística paulina em ambiente helenístico, Alfred Wikenhauser defende que, pelo batismo, o cristão é inserido objetivamente na união com Cristo. Todavia, em termos subjetivos, essa união somente se concretiza quando o cristão é capaz de vivê-la em âmbito religioso e ético. ${ }^{9}$

Se o termo mística, como se nota desde os primeiros autores, reveste-se de controvérsia nos estudos paulinos, ${ }^{10}$ não é controverso, porém, entre os exegetas o fato de que o termo não deva ser identificado com a experiência de fenômenos extraordinários, nem tampouco com fenômenos de tipo parapsicológico. ${ }^{11}$

${ }^{4}$ Cf. REITZENSTEIN, R. Die hellenistichen Mysterienreligionen nach ihren Grundgedanken und Wirkungen. Leipzig: Teubner, 1910, pp. 417-425.

${ }^{5}$ Cf. Para uma visão detalhada do status quaestionis cf. PENNA, R. "Problemi e natura della mistica paolina”. In: PENNA, R. L'apostolo Paolo. Studi di esegesi e teologia. Cinisello Balsamo (Milano): Paoline, 1991, pp. 630-638; BORRELL, A. "La mística paulina”. In: PUIG I TÀRRECH, A. (Ed.). Bíblia i mística. Montserrat: l'Abadia de Montserrat, 2011, pp. 159-175; MARGUERAT, D. "Paul le mystique". Revue Théologique de Louvain 43 (2012), pp. 473-493.

${ }^{6}$ Cf. SCHWEITZER, A. Die Mystic des Apostels Paulus. Tübingen: Mohr Verlag, 1930.

${ }^{7}$ Cf. SCHWEITZER, A. Die Mystic des Apostels Paulus, pp. 99-100.

${ }^{8}$ Cf. SCHWEITZER, A. Die Mystic des Apostels Paulus, pp. 90ss.

${ }^{9}$ Cf. WIKENHAUSER, A. Die Christusmystic des Apostels Paulus. 2 ed. Freiburg: Herder, 1956 , p. 66.

${ }^{10}$ Cf. SANDERS, E. P. Paul and Palestinian Judaism. A comparison of Patterns of Religion. Philadelphia; London: Fortress Press, 1977, p. 434, n. 19.

${ }^{11}$ Cf. No dizer de Rahner, a mística se identifica com uma autêntica experiência existencial de Deus. Cf. RAHNER, K. “Christsein in der Kirche der Zukunft”. Orientierung 44 (1980), pp. 65-67. 
Mesmo sabendo que Paulo relata, em algumas ocasiões, episódios admiráveis (cf. 1Cor 14,18; 2Cor 12,1-4) que poderiam confundir o leitor quanto ao sentido do termo mística, é preciso recordar que, enquanto filho da tradição judaica, Paulo não deveria ser adepto da religião com experiência de fenômenos extraordinários. ${ }^{12}$ Pelo contrário, a consciência mística em Paulo relaciona-se não ao fenômeno extraordinário, mas à consciência extraordinária da presença de Deus em sua vida, por meio de Cristo. Por esse motivo, a figura de Cristo é determinante, pois é por meio dele, único mediador, que a união mística com Deus é possibilitada. ${ }^{13}$ Daí decorre que o "estar em Cristo" fundamenta a originalidade do pensamento místico paulino, ${ }^{14}$ o que levou os autores alemães a dizerem que, em Paulo, parece mais correto falar de uma Gottesmystik que de uma Christusmystik. ${ }^{15}$ Se assim não fosse, estaríamos em um ambiente de experiência de Deus em concepção pagã ou hebraica, mas não cristã. ${ }^{16}$

Portanto, Paulo é um místico, no sentido de que suas experiências pessoais, fruto de sua relação espiritual com Cristo e, por meio dele, com Deus Pai, diferem das experiências da vida comum. ${ }^{17}$ Ele vive uma união de existência e de vida com o Cristo que, segundo Wikenhauser, não é somente uma experiência, mas é um estado. ${ }^{18}$

\section{1. "Com Cristo estou crucificado": a novidade semântica do lexema}

Em G1 2,19b, Paulo usa o verbo systaurō̄ (crucificar com), termo raro no NT, ${ }^{19}$ onde se encontra somente cinco vezes (cf. Mt 27,44; Mc 15,32; Jo 19,32; Rm 6,6 e G1 2,19).

Enquanto que nos evangelhos o verbo aparece no contexto da crucifixão

${ }^{12}$ Cf. CERFAUX, L. O Cristão na Teologia de Paulo. São Paulo: Academia Cristã; Paulus. 2012, p. 374.

${ }^{13}$ Cf. PIERI, F. L'itinerario di cristificazione di Paolo di Tarso. Caratteristiche di una esperienza di Dio. Roma: Gregorian \& Biblical Press, 2010.

${ }^{14}$ Cf. O’BRIEN, P. T. "Misticismo”, p. 844.

${ }^{15}$ Cf. PENNA, R. "Paulo (são)". In: BORRIELO, L; CARUANA, E.; DEL GENIO, M. R.; SUFFI, N. (Eds.). Dicionário de mística. São Paulo: Paulus; Loyola, 2003, p. 854.

${ }^{16}$ Cf. PENNA, R. "Problemi e natura della mistica paolina", p. 671.

${ }^{17}$ Cf. TANNEHILL, R. C. Dying and Rising with Christ. A Study in Pauline Theology. Berlin: Verlag Alfred Töpelmann, 1967, p. 4.

${ }^{18}$ Cf. WIKENHAUSER, A. Die Christusmystic des Apostels Paulus, p. 57.

${ }^{19}$ Segundo Chapman, o termo grego é um neologismo neotestamentário. Cf. CHAPMAN, D. W. Ancient Jewish and Christian Perceptions of Crucifixion. WUNT 2/244. Tübingen: Mohr Siebeck, 2008, p. 9, n. 38 . 
de Jesus e diz respeito à presença dos ladrões que foram crucificados com Cristo, ou seja, tiveram sua cruz posta ao lado da cruz de Cristo no calvário, em Paulo, o termo reveste-se de outro sentido.

Em Rm 6,6 ele diz: "sabendo que o nosso homem velho foi crucificado com..." o contexto indica claramente que o homem velho foi crucificado com Cristo e não em outra cruz. Em termos imagéticos, o lexema que nos sinóticos indica uma cruz ao lado de outra, já que os ladrões não foram postos à mesma cruz de Cristo, ${ }^{20}$ aqui aponta outro sentido: a cruz é uma só e a preposição syn (com) do verbo systauroō (crucificado com) indica que o homem velho está crucificado com Cristo, embora não apareça explicitamente no texto grego o complemento dativo. No entanto, em G1 2,19b Paulo diz que está crucificado com Cristo e aqui menciona o complemento dativo (com Cristo) explicitamente. Esses elementos abrem o caminho para o fio condutor basilar deste artigo: a cruz no corpus paulinum é somente a cruz de Cristo. Para o apóstolo, o termo nunca possui um valor antropológico geral, mas sempre e somente um valor cristológico: "não há outra cruz a não ser aquela de Cristo". ${ }^{21}$

Vejamos essa questão, um pouco mais de perto, nos dois contextos em que o verbo aparece.

Em Rm 6,6, encontramos a imagem do homem velho que foi crucificado com Cristo. Quando ocorreu essa crucifixão? Ou em outras palavras quando o homem velho foi posto à morte? No batismo, como parece sugerir Rm 6,4a ou no momento da morte de Cristo, como é o caso de Rm 7,4a? Alguns autores, em base ao contexto precedente (cf. Rm 6,3-4), defendem que simbolicamente, a morte ocorre no momento do batismo do cristão; ${ }^{22}$ outros, por sua vez, são do parecer que uma referência ao batismo em Rm 6,6 não seja facilmente identificável. ${ }^{23}$ Antonio Pitta, por exemplo, considera que no momento do

\footnotetext{
${ }^{20}$ Significativo perceber que em Mt 27,44 e em Mc 15,32, além da presença do prefixo "sy" em "systauroō", os evangelistas acrescentam a preposição "syn" seguida do pronome pessoal referente a Jesus no dativo; algo que Jo 19,32 não faz. Em Paulo, naturalmente, era de se esperar que não houvesse a repetição da preposição "syn" pelo simples fato de ser uma e única cruz.

${ }^{21}$ PENNA, R. "Sapienza e stoltezza della croce, fondamento della Chiesa”. In: PENNA, R. L'apostolo Paolo. Studi di esegesi e teologia. Cinisello Balsamo (Milano): Paoline, 1991, p. 429.

${ }^{22}$ Cf. BETZ, H. D. Galatians. A Commentary on Paul's Letter to the Churches in Galatia. Philadelphia: Fortress, 1979, p. 123; MATERA, F. J. Galatians. Collegeville, Minnesota: The Liturgical Press. 1992, p. 95; BECKER, J; LUZ, U. Die Briefe an die Galater, Epheser und Kolosser. Göttingen: Vandenhoeck \& Ruprecht, 1998, p. 44.

${ }^{23}$ Cf. WEDDERBURN, A. J. M. Baptism and Resurrection. Studies in Pauline Theology against Its Graeco-Roman Background. Tübinger: Mohr Siebeck, 1987, p. 49s.; PITTA, A. Lettera ai Romani. Nuova versione, introduzione e commento. Milano: Paoline, 2001, p. 250.
} 
batismo, aqueles que creem em Cristo são inseridos no mistério da cruz de Cristo, mas o foco é antes a cruz de Cristo e não o batismo do cristão. Em outras palavras, segundo ele, a perspectiva paulina aqui seria histórico-salvífica e não sacramentária. ${ }^{24}$ Romano Penna, consciente da questão, defende a intenção de Paulo em trazer aos romanos, no contexto de Rm 6,1-11, a reflexão sobre o tema da morte de Cristo e, consequentemente, do momento batismal. ${ }^{25}$

De qualquer forma, é preciso estar atento ao verbo presente em $\mathrm{Rm}$ 6,6: o aoristo passivo synestaurōthe (foi crucificado com). Por se tratar de um aoristo, indica uma ação específica no passado e poderia apontar, em termos locativos, tanto o evento histórico-salvífico cruz como defende Pitta, mas também o evento sacramental batismo, como defendem muitos outros exegetas. ${ }^{26} \mathrm{Se}$ partimos da concepção de que a cruz em Paulo é somente a de Cristo, então precisamos também admitir em termos teológicos sua precedência em relação ao batismo, pois sem ela, esse não teria sentido. Com efeito, é a partir de uma profunda compreensão do Mistério Pascal de Cristo que se compreendem, também, os sacramentos da Igreja, dentre os quais, o batismo. ${ }^{27}$ Contudo, para além dessas discussões, é nosso intento agora focarmo-nos, particularmente, no uso plural ("nosso homem velho") e na forma do verbo no aoristo passivo em Rm 6,6, como ponte para a compreensão do uso de systaurō em Gl 2,19b.

Em Gl 2,19b, systauroō não se encontra no aoristo, mas no perfeito e, em referência ao verbo, não encontramos a primeira pessoa plural como em Rm 6,6 (nosso homem velho), mas a primeira pessoa singular (com Cristo estou crucificado). Embora no contexto de Romanos, Paulo se insira na eclesialidade do plural expresso pelo pronome, pois ele também, pelo batismo, foi inserido em uma nova dimensão soteriológica como qualquer cristão; em Gl 2,19b, no entanto, a interpretação do verbo parece caminhar em outra direção.

$\mathrm{O}$ uso do perfeito passivo indica imageticamente que ele foi unido no

\footnotetext{
${ }^{24}$ Cf. PITTA, A. Lettera ai romani, p. 250.

${ }^{25}$ Cf. PENNA, R. "Battesimo e partecipazione alla morte di Cristo in Rom 6,1-11". In: PENNA, R. L'apostolo Paolo. Studi di esegesi e teologia. Cinisello Balsamo (Milano): Paoline, 1991, p. 163. Ele recorda que, no rito do batismo, a imersão significa o morrer junto com Cristo e a emersão, o ressurgir junto com Ele (cf. p. 161).

${ }^{26}$ Veja, a propósito, o que diz GONZAGA, W. "A Verdade do Evangelho” (Gl 2,5.14) e a autoridade da Igreja. Gl 2,1-21 na exegese do Vaticano II até nossos dias. História, balanço e novas perspectivas. Roma: Editrice Pontificia Università Gregoriana, 2007, p. 337, n. 848 e p. 345, n. 890 , justificando a conexão do conteúdo do versículo com o tema do sacramento do batismo.

${ }^{27}$ Cf. ROCCHETTA, C. Os Sacramentos da fé. Ensaio de teologia bíblica sobre os sacramentos como "maravilhas da salvação" no tempo da Igreja. São Paulo: Paulinas, 1991, pp. 261-262.
} 
passado a Cristo crucificado e, no momento presente em que emite a fala, ainda continua na mesma união. ${ }^{28}$

Se consideramos que G1 2,19b faz parte da perícope G1 2,15-2129, então é preciso observar algo que não pode passar despercebido: enquanto que nos versículos 15-17 o apóstolo usa o plural de primeira pessoa, nos versículos 18-21 ele passa a usar o singular de primeira pessoa.

No v. 15 o pronome "nós", se pensamos ao contexto do incidente em Antioquia (cf. Gl 2,11-14), poderia referir-se a Pedro, Barnabé e Paulo. No entanto, o tom generalizante parece indicar a totalidade do grupo de judeus que aderiram a Cristo pela profissão de fé seguida do batismo. ${ }^{30}$ Com efeito, no v. 16, o apóstolo recorda que não há justificação pelas obras da Lei, mas pela fé em Jesus Cristo. Obras da Lei que aqui, pelo contexto, parecem indicar o debate sobre a circuncisão na assembleia de Jerusalém (cf. G1 2,1-10) e a discussão sobre as leis alimentares no episódio de Antioquia (cf. Gl 2, 11-14). ${ }^{31}$

No v. 18, passa-se da primeira pessoa plural à primeira singular e assim permanece o discurso até o v. 21. Paulo recorre à diatribe, estilo usado pela primeira vez no conjunto da carta aos Gálatas. ${ }^{32}$ Nesse contexto, a argumentação em Gl 2,19b-20 é formada pela presença de um paralelismo concêntrico: ${ }^{33}$

$+[\mathrm{A}]$ Com CRISTO estou crucificado

- [B] Vivo, porém não mais eu; vive em mim CRISTO.

: [C] O que agora vivo na carne,

- [B'] na fé vivo do FILHO DE DEUS

$+\left[\mathrm{A}^{\prime}\right]$ que me amou e se entregou a si mesmo por mim.

\footnotetext{
${ }^{28}$ Cf. ELOY E SILVA, L. H. “O sofrimento apostólico de Paulo”. Coletânea 13 (2008), p. 130. ${ }^{29}$ Intitulada por Pitta de "mimesi paolina”. Cf. PITTA, A. Lettera ai Galati. Introduzione, versione e commento. Bologna: Edizioni Dehoniane Bologna, 2007, p. 138.

${ }^{30}$ Cf. PITTA, A. Lettera ai Galati, p. 140.

${ }^{31}$ Cf. DUNN, J. D. G. "A Teologia da Carta aos Gálatas: a questão do nomismo da aliança". In: DUNN, J. D. G. A nova perspectiva sobre Paulo. Santo André (SP): Academia Cristã; São Paulo: Paulus, 2011, p. 278.

${ }^{32}$ Cf. PITTA, A. Lettera ai Galati, p. 147.

${ }^{33}$ Cf. MEYNET, R. Trattato di Retorica Biblica. Bologna: Centro editoriale dehoniano, 2008, p. 252. Alguns autores chamam à estrutura semelhante à de Gl 2,19b-20 de quiasmo e outros de estrutura concêntrica. A terminologia não encontra consenso. De nossa parte, preferimos chamar a quiasmo, em sentido estrito, à estrutura de quatro membros cruzados em forma de $\mathrm{X}$, sem o elemento central. Veja, ainda, MEYNET, R. "E ora, scrivete per voi questo cantico". Introduzione pratica all'analisi retorica. Roma: Edizioni Dehoniane, 1996, p. 27; ALETTI, J.-N.; GILBERT, M.; SKA, J.-L.; VULPILLIÈRES, S. Vocabulário ponderado de exegese bíblica. São Paulo: Loyola, 2011, p. 115.
} 
Pela natureza da forma concêntrica, todos os termos que a compõem se interrelacionam, aqui porém em relação centrípeda, pois há um movimento hermenêutico que se encaminha em direção ao centro da estrutura.

No centro, encontra-se o "agora" de Paulo, marcado pelo presente do "viver na carne", na condição que o aproxima de todos os seres humanos, embora em uma nova dimensão espiritual e mística que o distancia, ${ }^{34}$ como é justificado pelos demais membros da estrutura concêntrica.

De fato, a sua condição é, ao mesmo tempo, de alguém crucificado, mas vivo! O perfeito passivo indica, em grego, que Paulo foi crucificado com Cristo em algum momento anterior ao da fala e, ao falar, continua ainda no mesmo estado [A]. No entanto, a relação com [A'] nos indica necessariamente que o paralelismo semântico não prioriza a pessoa do apóstolo, mas a do Cristo que o amou e entregou-se a si mesmo por ele. Os verbos amar (agapaō) e entregar-se (paradidōmi), encontram-se aqui no aoristo, respectivamente nas formas participiais agapésantos e paradidontos, o que põe [A'] hermeneuticamente antes de [A], pois o estar unido a Cristo crucificado deriva histórica e teologicamente da entrega de Cristo, por amor, sobre o madeiro. Se não bastasse isso, a própria condição dos particípios no aoristo marca um momento pontual no passado, pela entrega amorosa, o que não acontece com o perfeito passivo. Nesse caso, a imagem do "estar crucificado com" (synestaurōmai) é traçada como algo iniciado no passado mas com efeitos presentes.

Nas partes [B] e [B'] deparamo-nos com o campo semântico da vida expresso pelo verbo $z a \bar{o}$ (viver) que aparece $4 \mathrm{x}$ no v.20 e sempre no presente ativo. Esse dado é significativo pois indica a perenidade da vida que é presente e sobre a qual e a partir da qual Paulo fala. Ainda que possa parecer óbvio que alguém somente fale enquanto está vivo, o que poderia desqualificar aparentemente a importância de $z a \bar{o}$ no presente aqui, não podemos nos esquecer de que Paulo está no mundo da linguagem simbólica, que é real, como se pode deduzir também pelo uso do verbo morrer no v. 19a em que o apóstolo usa a forma no aoristo (apethanon) para indicar que morreu.

No entanto, é imprescindível notar que a carne em que Paulo vive é uma carne crucificada, devido ao uso do perfeito no v.19b. ${ }^{35}$ Em outras palavras,

\footnotetext{
${ }^{34}$ Cf. PITTA, A. Lettera ai Galati, p. 152.

${ }^{35}$ Como nota Merklein: "das Mit-Christus-grekreuzigt-Sein (ist) die bleibende Existenz des Gerechtfertigten": MERKLEIN, H. "Die Bedeutung des Kreuzestodes Christi für die paulinische Gerechtigkeits- und Gesetzesthematik". In: MERKLEIN, H. Studien zu Jesus und Paulus. Tübingen: Mohr Siebeck, 1987, p. 50.
} 
Paulo vive e vive na graça da vida de Cristo que vive nele no presente, mas é um presente crucificado. Significativo, ainda, perceber o uso dos dativos de sentido locativo místico. Em 2,19b Cristo vive em Paulo, o que é de se supor que não somente Cristo vive no apóstolo, mas também o apóstolo vive em Cristo, devido ao uso da preposição syn (com) presente no verbo systauroo ${ }^{36}$ Expressamente, no entanto, o uso do dativo na estrutura sintática em que Paulo é o sujeito do verbo vincula o apóstolo à carne e à fé. Em [C] ele diz que vive o agora "na carne" e em [B'] recorda que ele vive "na fé do Filho de Deus". O segundo dativo exerce função epexegética em relação ao primeiro, e indica que a sua vida não é vivida independente por si mesmo, mas na dependência do Filho de Deus, pela fé. ${ }^{37}$

\section{2. "Com Cristo estou crucificado": campo semântico e hermenêutica}

Como se pode deduzir do percurso anterior, o uso paulino do verbo systauroō reveste-se de particular relevo em G1 2,19b. Enquanto em Rm 6,6 ao termo refere-se o "nós" eclesial no qual se insere naturalmente Paulo, em G1 2,19b ele usa a primeira pessoa do singular referindo-se a si mesmo, enquanto pessoa. É preciso dar um passo ulterior na compreensão do v. $19 \mathrm{~b}$ em relação a 20b, particularmente buscando compreender a relação entre a cruz, o eu do apóstolo e o verbo systauroō no perfeito passivo.

Antes, porém, é preciso verificar o campo semântico da cruz no epistolário paulino. Nota-se que ele é rico: Paulo utiliza o substantivo stauros (cruz) usado 10x das 27x no NT em 1Cor 1,17.18; G1 5,11; 6,12.14; Ef 2,16; F1 2,8; 3,18; Col 1,20; 2,14; o verbo stauroō (crucificar) usado $8 \mathrm{x}$ das $46 \mathrm{x}$ no NT em 1 Cor $1,13.23$; 2,2.8; 2 Cor 13,4; G1 3,$1 ; 5,24 ; 6,14$; o verbo systauroo (crucificar com) usado $2 \mathrm{x}$ das $5 \mathrm{x}$ no NT em Rm 6,6 e G1 2,19; o substantivo xylon (cruz) usado 1x das 5x no NT em Gl 3,13; o verbo kremannymi (pendurar) usado 1x das

\footnotetext{
${ }^{36}$ Como recorda bem Romano Penna, o uso dos complementos e compostos com syn no corpus paulinum indica o tema da participação unitiva com Cristo. Cf. PENNA, R. "Battesimo e partecipazione alla morte di Cristo in Rom 6,1-11”, p. 163. Note-se também CERFAUX, L. $O$ Cristão na Teologia de Paulo, p. 349, n. 825.

${ }^{37}$ Cf. BURTON, E. W. A Critical and Exegetical Commentary on the Epistle to the Galatians. Edinburgh: T\&T Clark, 1988, p. 138. Semelhantemente, FARAHIAN, E. Le "je” paulinien. Etude pour mieux comprendre Gal 2,19-21. Analecta Gregoriana. Roma: Gregorian \& Biblical Press, 1988, p. 253.
} 
4x no NT em Gl 3,13 e o hapax legomenon proseloō (cravar) em Col 2,14. ${ }^{38}$

Aqui, de modo mais atento, é mister observar o que ocorre com o campo semântico no texto de Gálatas, primeiro em função de nossa proposta hermenêutica e, depois, pela própria entrada das ocorrências que, em sua maioria, encontram-se nessa carta.

Como se vê, o termo stauros encontra-se em Gl 5,11; 6,12.14; o verbo stauroō em G1 3,1; 5,24; 6,14; o verbo systaurō em G1 2,19b e o substantivo xylon em Gl 3,13.

Não levando em conta nesse momento o termo systauroō, visitaremos os outros termos seguindo a ordem em que aparecem na sequência dos capítulos.

Em Gl 3,1, aparece a forma participial de stauroō no perfeito passivo (estaurōmenos) referente a Cristo que é apresentado como aquele foi crucificado e continua crucificado, devido ao uso do perfeito.

Em Gl 3,13, fala-se daquele que está pendurado no madeiro como um maldito. Note-se o uso do presente de pendurado no particípio passivo (kremamenos) que aqui traduzimos por "está pendurado".

Em G1 5,11, Paulo argumenta que se ele ainda prega a circuncisão, não tem sentido a perseguição que sofre e, logo, "está desfeito" o escândalo da cruz. Mais uma vez ao referir-se à cruz, aqui como escândalo, o apóstolo usa o perfeito passivo (katērgētai) que traduzimos por "está desfeito".

Em G1 5,24, Paulo fala dos que são de Cristo e crucificaram a carne com suas paixões e desejos. Ao usar o verbo crucificaram no aoristo (estaurōsan) e não no presente, o apóstolo indica a participação na morte de Cristo como algo preciso e pontual em algum momento do passado. ${ }^{39}$

Em Gl 6,12, Paulo recorda que os que querem mostrar-se em boa aparência na carne, são os que forçam os gálatas a circuncidarem-se para não sofrerem perseguição por causa da cruz de Cristo.

Em 6,14, Paulo utiliza o substantivo stauros e o verbo stauroō dizendo "para mim, não aconteça gloriar-me senão na cruz de nosso Senhor Jesus Cristo, por meio do qual para mim o mundo está crucificado e eu para o mundo". O verbo stauroō aparece no passivo perfeito (estaurōtai) que aqui traduzimos por "está crucificado".

\footnotetext{
${ }^{38}$ Cf. REYNIER, C. "La langage de la croix dans le corpus paulinien". In: SCHLOSSER, J. (Ed.). Paul de Tarse. Association Catholique Française pour 1'Étude de la Bible. Paris: Les éditions du Cerf, 1996, p. 362, n. 1.

${ }^{39}$ Cf. PITTA, A. Lettera ai Galati, p. 367. Mais uma vez, como recorda o exegeta italiano na mesma página, há autores que vinculam a passagem ao evento do batismo.
} 
Após este breve percurso dos termos, nota-se que das sete entradas, cinco delas referem-se à cruz de Cristo somente (cf. Gl 3,1.13; 5,11; 6,12.14) e as outras duas têm uma particularidade: uma refere-se aos cristãos, em geral, que com Cristo crucificaram sua carne (cf. Gl 5,24); e a outra refere-se especificamente ao apóstolo que por Cristo considera que o mundo está crucificado para si e ele para o mundo (cf. Gl 6,14).

Particularmente, o discurso presente em Gl 6,14 nos vincula a Gl 2,19b devido à aproximação do conteúdo. Mesmo que aqui não apareça o verbo systauroō, o conteúdo é muito semelhante. Com efeito, Paulo se gloria na cruz de Cristo que continua crucificado (estaurōtai: perfeito passivo) e, por meio de Cristo, o mundo está para Paulo crucificado e ele para o mundo.

Se por um lado, o uso do perfeito causa estupor, pois indica o estar crucificado permanentemente pela ação do verbo que teve um início no passado e, todavia, mantém seus efeitos no presente, é preciso com isso compreender não que Jesus ainda esteja sobre a cruz, mas que mesmo tendo ressuscitado será sempre o crucificado, ${ }^{40}$ como se deduz de sua aparição aos discípulos no evangelho de João, especialmente no episódio em que se encontra com Tomé e pede-lhe para que ponha o dedo em suas chagas, cujas marcas revelam-no como o ressuscitado-crucificado (cf. Jo 20,27).

Se o perfeito pôs-nos diante desse horizonte semântico, o mesmo pode-se dizer do fato de o verbo aparecer em G1 2,19b e em Gl 6,14 na voz passiva. Embora possa parecer óbvio que ninguém crucifique a si mesmo em sentido literal, é preciso entender que no contexto do estar crucificado com Cristo põe-nos diante de uma questão elucidativa, mas ao mesmo tempo complexa.

Quando dizemos que a cruz em Paulo é sempre a cruz de Cristo, nos perguntamos sobre a máxima discipular presente em Mc 8,34; Mt 16,24 e Lc 9,23 . Com efeito, nos textos mencionados, Jesus convoca o discípulo a tomar a própria cruz e a segui-lo. Em outras palavras, segundo a tradição sinótica, além da cruz de Cristo, o discípulo é chamado a carregar a própria cruz. Para o apóstolo dos gentios não existe uma cruz do cristão, mas única e somente a cruz de Cristo. Logo, não se pode falar da dimensão da cruz em sentido ativo, como nos sinóticos, em que o discípulo toma a cruz e, renunciando ou negando a si mesmo, segue o mestre. Pelo contrário, Paulo fala de si mesmo usando o passivo, pois não foi ele que tomou a cruz e nem mesmo a buscou; foi-lhe dada.

${ }^{40}$ Cf. BURTON, E. W. A Critical and Exegetical Commentary on the Epistle to the Galatians, p. 145. 
Além disso, segundo o relato do encontro de Saulo de Tarso com Jesus na estrada de Damasco, presente em At 9,15-16, fica claro, pelo contexto, que a iniciativa do chamado é de Cristo, constituindo o perseguidor dos cristãos em vocacionado à missão apostólica quando se lê que Saulo foi escolhido para levar o nome de Jesus diante das nações gentias, dos reis e dos israelitas (cf. At 9,15$)$ e que o próprio Cristo lhe haveria de mostrar o quanto seria preciso sofrer por causa de seu nome (cf. At 9,16).

O tema do sofrimento, segundo At 9,16, é expresso pelo verbo paschō, termo que no NT, em sua maioria, refere-se à paixão de Cristo e aos sofrimentos que os cristãos são chamados a viver por amor a Cristo. ${ }^{41}$ No epistolário paulino, a maior parte em que o verbo aparece é para referir-se aos cristãos em geral. São poucos os casos em que o apóstolo refere-se a si mesmo com o verbo paschō; pelo contrário, ele prefere usar o termo pathēma em relação a si próprio.

O verbo paschō encontra-se no corpus paulinum 7 vezes: 1 Cor 12,26; 2 Cor 1,6; Gl 3,4; Fl 1,29; 1Ts 2,14; 2Ts 1,5; 2Tm 1,12. Nas seis primeiras entradas, o verbo refere-se ao sofrimento do cristão em geral enquanto membro da comunidade eclesial, corpo de Cristo, o que de alguma forma significa sofrer por Cristo (cf. Fl 1,29). Somente em 2Tm 1,12, claramente pelo contexto, Paulo fala dos sofrimentos em primeira pessoa singular associando-os a Cristo, em quem depositou sua fé. ${ }^{42}$

O substantivo pathèma, por sua vez, aparece 9 vezes no epistolário: Rm 7,5; 8,18; 2Cor 1,5.6.7; G1 5,24; Fl 3,10; Cl 1,24; 2Tt 3,11. Por 7 vezes, o termo relaciona-se aos sofrimentos do apóstolo ou do cristão em geral.

Paulo fala de pathèma por antíteses. Ele usa o binário cronológico passado/presente; presente/futuro ou fala simplesmente no presente usando a contraposição entre imagens semânticas.

Em Rm 7,5-6 e G1 5,24, nota-se a contraposição passado/presente. Em Rm 7,5-6, o apóstolo fala literalmente de "sofrimentos dos pecados". A Nova Vulgata traduziu pathēmata aqui por "passiones" (paixões), sentido também compreendido pela maioria das traduções contemporâneas. Por sua vez, Gl 5,24 usa o termo pathēmasin traduzido pela Nova Vulgata como "vitiis" e pela maioria das traduções contemporâneas como "paixões".

${ }^{41}$ Cf. MICHAELIS, W. "Paschō”. In: KITTEL, G; FRIEDRICH, G. Theologisches Wörterbuch zum Neuen Testament. Stuttgart: W. Kohlhammer Verlag, 1959, Band V, p. 910.

${ }^{42}$ Cf. ELOY E SILVA, L. H. "Pablo, apóstol por la gracia y de la gracia, testigo del Misterio Pascual de Cristo". La Revista Católica, abril/junio (2009), p. 123. 
Em Rm 8,18; 2Cor 1,7 e Fl 3,10 nota-se a contraposição presente/futuro, onde prevalece o campo semântico do sofrimento presente e da glória futura; mas também do sofrimento presente e da consolação futura e, ainda, da morte e ressurreição. Em outras palavras, os sofrimentos do presente por causa de Cristo não se comparam à glória que haverá de ser revelada (cf. Rm 8,18) ou à consolação que está reservada ao cristão (cf. 2Cor 1,7).

Um terceiro grupo diz respeito ao tempo presente no qual são contrapostos os sofrimentos e a consolação (cf. 2Cor 1,5.6) e os sofrimentos e o regozijo (cf. Fl 3,10) e, semelhantemente, no passado, devido ao uso de três aoristos, nota-se a contraposição entre perseguições e sofrimentos de um lado, e a libertação dos mesmos pelo Senhor, de outro (cf. 2Tm 3,11).

Se retomamos esse percurso a partir da compreensão da vocação paulina, como expresso no relato lucano, notamos que o apóstolo foi misteriosamente associado à cruz de Cristo, pois é o próprio Senhor quem diz a Ananias que haveria de mostrar a Saulo, o quanto ele iria sofrer por seu nome (cf. At 9,16). A associação ao mistério pascal de Cristo se dá por graça, como dom de Deus (cf. Ef 2,8-9). O apóstolo sente-se "tomado, alcançado, conquistado" (katelèmphthēn [cf. F1 3,12]), o que indica de per se a compreensão de que "a santidade não se mede em termos morais, como meta a ser alcançada com o próprio esforço ou, dito de outra forma, através das próprias obras; (...) é dimensão pré-dada", ${ }^{43}$ objetivamente pelo sacramento do batismo. ${ }^{44}$ Em outras palavras, para Paulo a perfeição cristã "não é apenas o objetivo, mas o status de cada indivíduo que crê". ${ }^{45}$

\section{Conclusão}

A partir do momento em que pelo batismo o cristão é unido a Cristo, o ressuscitado-crucificado, ele comunga do mistério da vida de Cristo, morrendo cotidianamente ao pecado e renascendo à vida nova em Cristo (cf. 1 Cor 15,31). Nesse sentido, todo batizado está inserido no mistério pascal de Cristo e, mesmo vivendo nos limites característicos do ser na história, tende às coisas do alto (cf. $\mathrm{Cl} \mathrm{3,1),} \mathrm{pois} \mathrm{a} \mathrm{dimensão} \mathrm{ontológica} \mathrm{do} \mathrm{"ser} \mathrm{em} \mathrm{Cristo"} \mathrm{é} \mathrm{dom}$ recebido no batismo por todo cristão.

\footnotetext{
${ }^{43}$ PENNA, R. "Paulo (são)", p. 855.

${ }^{44}$ Cf. ELOY E SILVA, L. H. "Pablo, apóstol por la gracia y de la gracia, testigo del Misterio Pascual de Cristo", pp. 125-126.

${ }^{45}$ PENNA, R. "Paulo (são)", p. 856.
} 
Contudo a consciência de tal realidade não é compreensão de todo cristão. Com efeito, a afirmação "com Cristo estou crucificado. Vivo, porém não mais eu; vive em mim Cristo" somente poderá ser especificamente compreendida na dimensão do que seria o que chamaríamos de "consciência mística". É ela que permite a quem fez a experiência de morrer para si e viver para o Senhor ser capaz de verbalizar-se e, consequentemente, verbalizar sua experiência espiritual por meio de tal metáfora tão profunda. ${ }^{46}$

Nesse sentido, discordamos dos que consideram o pronome de primeira pessoa singular usado pelo apóstolo como mero artifício retórico representativo da coletividade cristã. ${ }^{47} \mathrm{Nem}$ todo cristão haverá de chegar a tal consciência. Obviamente pelo batismo, todo cristão é inserido em Cristo e vive a ele unido por fazer parte concomitantemente da Igreja que é seu corpo cuja vida não pode vir senão da cabeça que é ele mesmo (cf. Ef $1,22-23 ; 4,15 ; 5,23 ;$ Col 1,18). Contudo, embora todo cristão esteja inserido nesse mistério, nem todos haverão de viver uma experiência de união mística com Cristo, não como realidade ontológico-sacramental que é dom para todo cristão, mas enquanto consciência experiencial do que significa essa realidade.

Em termos objetivos, pela dimensão sacramental do batismo, o cristão vive em Cristo e Cristo vive nele, mas por consciência mística entendemos aqui não somente a assunção do que essa realidade significa, mas sua consequência concreta: a capacidade do cristão de pautar seu pensamento e vivência a partir da compreensão consciente e experiencial dessa mesma realidade. Tal compreensão não é estática mas dinâmica, pois passa necessariamente por uma evolução espiritual e consciencial, como ilustra bem S. Teresa de Jesus em seu Castelo Interior ao falar do processo que envolve as sete

${ }^{46}$ Cf. BALDINI, M. "Linguagem mística”. In: BORRIELO, L; CARUANA, E.; DEL GENIO, M. R.; SUFFI, N. (Eds.). Dicionário de mística, São Paulo: Paulus; Loyola, 2003, p. 641, recorda que "o místico é o homem das metáforas".

${ }^{47}$ Este é o caso de Mussner que, por exemplo, defende o "eu" como sendo coletivo do "nós" judeu-cristão expresso em Gl 2,15-17. Até admite que se trata de uma experiência particular do apóstolo, mas como expressão da realidade cristã e, portanto, característica de todos os batizados. Cf. MUSSNER, F. Der Galaterbrief. (HThKNT IX). Freiburg-Basel-Wien: Herder, 1974, p. 182s. Com efeito, sustenta Farahian, após sua longa pesquisa sobre o uso do pronome "eu" em Paulo, mesmo dentro dos diferentes ambientes e temas das diversas cartas, que se trata de um "eu autobiográfico". Por isso mesmo, em Gl 2,19-21 o pronome refere-se mais uma vez a Paulo e a ele somente". Em suas palavras: "nous soustenons que le "je" que l'on reencontre se réfère à Paul, et à lui seul". FARAHIAN, E. Le "je" paulinien. Étude pour mieux comprendre Gal 2,19-21, p. 254. 
moradas. ${ }^{48}$ Nesse sentido, não podemos concordar com Wikenhauser que atribui ao conceito mística "o estado objetivo de todos os cristãos" ${ }^{49}$ Concordamos, diversamente, quando ele diz que o cristão místico é aquele que produz em sua vida pessoal o que o batismo concedeu-lhe em termos comunitários ou eclesiais, entregando-se a si mesmo a Cristo que a partir dessa entrega passa a agir nele. ${ }^{50}$ Nesse sentido, a consciência da vida mística em Cristo poderia ser uma realidade de todo cristão. Contudo, na prática, não é uma realidade experimentada por cada cristão, pois o processo interior de entrega não ocorre em nível semelhante com todos os que estão no caminho; não devido à oferta da graça, que é dom oferecido a todos, mas à recepção pessoal do dom que toca necessariamente na dimensão da liberdade de cada indivíduo.

A linguagem mística somente pode ser expressão verbalizada ou calada, no som emitido ou no silêncio sonoro, pela boca daquele cujo coração fez a experiência profunda da comunhão com o amor do Cristo, que não pode ser jamais compreendido senão no solo fecundado pelo sangue de sua cruz, materialização eloquente de seu amor pelo ser humano, realidade que Paulo experimentou "na carne" ao escrever "que me amou e se entregou a si mesmo por mim" (G1 2,20).

Naturalmente a união mística do apóstolo com Cristo não tem o teor das categorias helenistas das religiões mistéricas em que o eu do sujeito tornava-se uma só coisa com a divindade. Pelo contrário, é preciso admitir que, para Paulo, Cristo tornou-se sua razão de ser e a expressão de sua identidade existencial "não pela troca, mas pelo distanciamento de papéis pessoais, como se dá com o servo em relação ao seu Senhor". ${ }^{51}$ Não há confusão de identidades entre Paulo e Cristo, pois o próprio apóstolo dirá em Gl 2,20 "vivo na fé do Filho de Deus", o que indica necessariamente "um face-a-face que põe cada um no seu devido lugar, sem perigosas misturas". ${ }^{52}$ Mesmo assim, Paulo está em estado permanente e presente de união com Cristo; união que o caracte-

\footnotetext{
${ }^{48}$ A santa fala do caminho espiritual como um processo em sete moradas. A sétima morada encontra-se no centro do castelo onde se dá a união mística entre a alma e Deus. Cf. SANTA TERESA DE JESUS, Castelo Interior, I, 3 e também a introdução do editor que justifica que em todo o processo das moradas a meta é sempre Cristo. In: SANTA TERESA DE JESUS, Obras Completas (texto estabelecido por Fr. Tomas Alvarez, O.C.D), São Paulo: Loyola, 1995, p. 437 e p. 442.

${ }^{49}$ WIKENHAUSER, A. Die Christusmystic des Apostels Paulus, p. 57.

${ }^{50}$ Cf. WIKENHAUSER, A. Die Christusmystic des Apostels Paulus, pp. 66-69.

${ }^{51}$ PENNA, R. "Paulo (são)", p. 857.

52 PENNA, R. "Paulo (são)”, p. 857.
} 
riza como um ser comungante da realidade soteriológica que deriva da cruz. E justamente por isso sua linguagem, ao falar de sua união com Cristo em Gl 2,19b-20, é mística, pois sua experiência é mística e mística sua vida, vida nova em Cristo, com quem está crucificado e por isso mesmo pode dizer, na consciência concreta e real que ele alcançou: "Vivo, porém não mais eu; vive em mim Cristo" (Gl 2,20).

\section{Referências bibliográficas}

ALETTI, J.-N.; GILBERT, M.; SKA, J.-L.; VULPILLIÈRES, S. Vocabulário ponderado de exegese bíblica. São Paulo: Loyola, 2011.

BALDINI, M. "Linguagem mística". In: BORRIELO, L; CARUANA, E.; DEL GENIO, M. R.; SUFFI, N. (Eds.). Dicionário de mística. São Paulo: Paulus; Loyola. 2003, pp. 640-642.

BECKER, J; LUZ, U. Die Briefe an die Galater, Epheser und Kolosser. Göttingen: Vandenhoeck \& Ruprecht, 1998.

BETZ, H. D. Galatians. A Commentary on Paul's Letter to the Churches in Galatia. Philadelphia: Fortress, 1979.

BORRELL, A. "La mística paulina”. In: PUIG I TÀRRECH, A. (Ed.). Bíblia $i$ mistica. Montserrat: l'Abadia de Montserrat, 2011, pp. 159-175.

BURTON, E. W. A Critical and Exegetical Commentary on the Epistle to the Galatians. Edinburgh: T\&T Clark, 1988.

CERFAUX, L. O Cristão na Teologia de Paulo. São Paulo: Academia Cristã; Paulus, 2012.

CHAPMAN, D. W. Ancient Jewish and Christian Perceptions of Crucifixion. WUNT 2/244. Tübingen: Mohr Siebeck, 2008.

DEISSMANN, A. Die neutestamentliche Formel "in Christo Jesu”. Marburg: N. G. Elwert, 1892.

DUNN, J. D. G. "A Teologia da Carta aos Gálatas: a questão do nomismo da aliança". In: DUNN, J. D. G. A nova perspectiva sobre Paulo. Santo André (SP): Academia Cristã; São Paulo: Paulus, 2011, pp. 261-288.

ELOY E SILVA, L. H. "O sofrimento apostólico de Paulo". Coletânea 13 (2008), pp. 117-132. 
ELOY E SILVA, L. H. "Pablo, apóstol por la gracia y de la gracia, testigo del Misterio Pascual de Cristo". La Revista Católica, abril/junio (2009), pp. 116-126.

FARAHIAN, E. Le “je” paulinien. Étude pour mieux comprendre Gal 2,1921. Analecta Gregoriana. Roma: Gregorian \& Biblical Press, 1988.

GONZAGA, W. “A Verdade do Evangelho” (Gl 2,5.14) e a autoridade da Igreja. Gl 2,1-21 na exegese do Vaticano II até nossos dias. História, balanço e novas perspectivas. Roma: Editrice Pontificia Università Gregoriana, 2007.

MARGUERAT, D. “La mystique de l'apôtre Paul”. In: SCHLOSSER, J. (Ed.). Paul de Tarse. Actes du XVIe Congrés de l'Association Catholique Française por l'Étude de la Bible. Paris: Les éditions du Cerf, 1996, pp. 307-329.

MARGUERAT, D. "Paul le mystique". Revue Théologique de Louvain 43 (2012), pp. 473-493.

MATERA, F. J. Galatians. Collegeville, Minnesota: The Liturgical Press, 1992.

MERKLEIN, H. "Die Bedeutung des Kreuzestodes Christi für die paulinische Gerechtigkeits- und Gesetzesthematik". In: MERKLEIN, H. Studien zu Jesus und Paulus. Tübingen: Mohr Siebeck, 1987, pp. 1-105.

MEYNET, R. “E ora, scrivete per voi questo cantico”. Introduzione pratica all'analisi retorica. Roma: Edizioni Dehoniane, 1996.

MEYNET, R. Trattato di Retorica Biblica. Bologna: Centro editoriale dehoniano, 2008.

MICHAELIS, W. "Paschō". In: KITTEL, G; FRIEDRICH, G. Theologisches Wörterbuch zum Neuen Testament. Stuttgart: W. Kohlhammer Verlag, 1959, Band V, pp. 903-922.

MUSSNER, F. Der Galaterbrief. (HThKNT IX). Freiburg-Basel-Wien: Herder, 1974.

O’BRIEN, P. T. "Misticismo”. In: HAWTHORNE, G. F.; MARTIN, R. P.; REID, D. G. (Orgs.). Dicionário de Paulo e suas Cartas. São Paulo: Paulus; Edições Vida Nova; Edições Loyola, 2008, pp. 843-846.

PENNA, R. "Battesimo e partecipazione alla morte di Cristo in Rom 6,1-11". 
In: PENNA, R. L'apostolo Paolo. Studi di esegesi e teologia. Cinisello Balsamo (Milano): Paoline, 1991, pp. 150-170.

PENNA, R. "Paulo (são)". In: BORRIELO, L; CARUANA, E.; DEL GENIO, M. R.; SUFFI, N. (Eds.). Dicionário de mística. São Paulo: Paulus; Loyola. 2003, pp. 854-858.

PENNA, R. "Problemi e natura della mistica paolina". In: PENNA, R. L'apostolo Paolo. Studi di esegesi e teologia. Cinisello Balsamo (Milano): Paoline, 1991, pp. 630-673.

PENNA, R. "Sapienza e stoltezza della croce, fondamento della Chiesa". In: PENNA, R. L'apostolo Paolo. Studi di esegesi e teologia. Cinisello Balsamo (Milano): Paoline, 1991, pp. 418-435.

PIERI, F. L'itinerario di cristificazione di Paolo di Tarso. Caratteristiche di una esperienza di Dio. Roma: Gregorian \& Biblical Press, 2010.

PITTA, A. Lettera ai Galati. Introduzione, versione e commento. Bologna: Edizioni Dehoniane Bologna, 2007.

PITTA, A. Lettera ai Romani. Nuova versione, introduzione e commento. Milano: Paoline, 2001.

RAHNER, K. "Christsein in der Kirche der Zukunft". Orientierung 44 (1980), pp. $65-67$.

REITZENSTEIN, R. Die hellenistichen Mysterienreligionen nach ihren Grundgedanken und Wirkungen. Leipzig: Teubner, 1910, pp. 417-425.

REYNIER, C. "La langage de la croix dans le corpus paulinien". In: SCHLOSSER, J. (Ed.). Paul de Tarse. Association Catholique Française pour l'Étude de la Bible. Paris: Les éditions du Cerf, 1996, pp. 361-373.

ROCCHETTA, C. Os Sacramentos da fé. Ensaio de teologia bíblica sobre os sacramentos como "maravilhas da salvação" no tempo da Igreja. São Paulo: Paulinas, 1991.

SANDERS, E. P. Paul and Palestinian Judaism. A comparison of Patterns of Religion. Philadelphia; London: Fortress Press, 1977.

SCHWEITZER, A. Die Mystic des Apostels Paulus. Tübingen: Mohr Verlag, 1930.

TANNEHILL, R. C. Dying and Rising with Christ. A Study in Pauline Theology. Berlin: Verlag Alfred Töpelmann, 1967. 
TERESA DE JESUS, Santa. Castelo Interior. In: TERESA DE JESUS, Santa. Obras Completas (texto estabelecido por Fr. Tomas Alvarez, O.C.D), São Paulo: Loyola, 1995, pp. 431-588.

WEDDERBURN, A. J. M. Baptism and resurrection. Studies in Pauline Theology against Its Graeco-Roman Background. Tübinger: Mohr Siebeck, 1987.

WIKENHAUSER, A. Die Christusmystic des Apostels Paulus. 2 ed. Freiburg: Herder, 1956.

\section{Luís Henrique Eloy e Silva}

Doutor em Ciência Bíblica pelo Pontifício Instituto Bíblico de Roma Professor na Pontifícia Universidade Católica de Minas Gerais (PUC MINAS)

Professor na Faculdade Jesuíta de Filosofia e Teologia (FAJE) Belo Horizonte / MG - Brasil E-mail: luishenrique@pucminas.br

Recebido em: 28/10/16 Aprovado em: 09/01/17 